\title{
Social Identity in a Service Organization: A Scale's Content and Construct Validity Social Identity Scale
}

\author{
María de la Luz Escalona, \\ Cirilo H. García, Eduardo Leal \\ Universidad Autónoma de Nuevo \\ León, Nuevo León, México
}

\author{
Luis F. Arias \\ Universidad Autónoma del Estado \\ de Morelos, Morelos, México
}

\author{
Francisco A. Treviño \\ Universidad Autónoma de Nuevo \\ León, Nuevo León, México
}

\begin{abstract}
Objective: This article describes the validation process of SOIS-12 (the social identity organizational scale) of Escalona and García. The purpose has been to establish the construct and content validity of this scale developed to measure the social identity of employees within a service organization. The validation process has taken into account the criticisms made of currently available measurement instruments. Method: The study sample consisted of 361 employees, 224 male and 137 female. Results: Statistical analyses revealed strong Cronbach alphas and goodness of fit. Discussion: The findings of this study provide support for the content validity and construct validity of a Latin American instrument to measure social organizational identity.

Keywords: organizational social identity, reliability, content validity, construct validity, confirmatory factor analysis.
\end{abstract}

\section{Introduction}

According to the Real Academia de la Lengua (2001) dictionary, identity is the "Unique combination of traits an individual or group of individuals that differentiate them from everybody else". Ashforth, Harrison, and Corley (2008) propose that identity is a concept of self-reference that lets the individual know who he or she is. Tajfel developed the Social Identity Theory and along with Turner has provided empirical support for the theory in many areas of social psychology where it has had a significant impact (Tajfel \& Turner, 1981). The theory proposes for instance that people within organizations have an intrinsic tendency to classify themselves as part of one or more groups, to identify with them and to protect the boundaries of such groups. Social identity enables people to identify with the distinctive characteristics of particular groups.

Tajfel (1978) has defined identity as that part of an individual's self-concept that stems from knowledge of his/her membership in one or more social groups as well as from the value or social significance attached to such memberships. Postmes and Jetten (2006, p. 260) in turn propose that personal identity is the sensation of being a unique human being and the sum of the person's idiosyncratic attributes such as characteristics, abilities and interests. In spite of the contributions of the previously stated authors, it has been suggested however that

María de la Luz Escalona, Facultad de Psicología, Universidad Autónoma de Nuevo León.

Cirilo H. García, Ph.D., Facultad de Psicología, Universidad Autónoma de Nuevo León.

Eduardo Leal, Ph.D., Facultad de Psicología, Universidad Autónoma de Nuevo León.

Luis F. Arias, Ph.D., Facultad de Psicología, Universidad Autónoma del Estado de Morelos.

Francisco A. Treviño, Ph.D., Universidad Autónoma de Nuevo León. 
Haslam and Ellemers (2005) have been the most influential proponents of the SIT/SCT (Social Identity Theory and Self-Classification Theory) (Ashforth, Harrison, \& Corley, 2008).

According to various authors, organizational success is based on performance. Success however requires that employees go beyond the completion of particular individual tasks and engage in extra-role activities (Van Knippenberg \& Ellmers, 2003; Podsakoff, Ahearne, \& Mackenzie, 1997). Yubero and Morales (2006) go a step further and propose that the development of social identity in organizations revolves around work teams and is not only related to willingness to perform in role or extra-role activities. Furthermore, these authors propose that organizational identity will positively impact work related outcomes such as job satisfaction, commitment, citizenship, and performance that goes beyond the assigned role.

Topa and Morales (2006) explored the relationship between identification with the organization and individual performance within work groups utilizing Tajfel's theory (1974). According to these authors, organizations often expect employees to commit to organizational missions and not only to carry out their individual job tasks. Organizations seek a constellation of behaviors such as: organizational citizenship, personal initiative, performance that goes beyond the basic requirements of the job, pro-social behavior, and contextual performance. All of these characteristics describe a self-starter engaged employee that promotes and protects the public image of the organization. The same authors highlight the fact that individual performance incentives do not necessarily produce organizational citizenship or personal initiative given that they respond to particular personal interests. Furthermore, they argue that organizations should concern themselves with making sure employees identify with the organization and its goals given that this is a prerequisite for increasing organizational productivity and enhancing its overall performance.

Ashforth and Mael (1989) have built on Tajfel and Turner's (1986) TIS by proposing that organizational identity is a form or type of social identity. They propose that the organization where a person works facilitates the development of his/her identity. For this reason, organizational identity is considered as form of social identity, which in turn serves as motivation to become more involved in organizational matters and work to accomplish organizational goals (Ashforth \& Mael, 1989; Van Knippenberg \& Van Shie, 2000).

Tompkins (2005) conducted pioneering work in the area of organizational communication and was one of the first scholars to use the organizational identification concept. Subsequently, Cheny and Tompkins (1987) clarified the concept as it applies to organizations. OIQ (the Organizational Identification Questionnaire), (Cheney, 1982) has made it possible for other researchers to conduct valuable studies related to organizational identity. Nevertheless, in spite of its frequent use, the instrument has been the object of criticisms (Miller, Allen, Casey, \& Johnson, 2000).

The original OIQ used by Tompkins and Cheney (1983) had 30 items. The use of the instrument has been criticized given that allegedly it was used by researchers who had not studied its internal structure. The lack of knowledge of the instrument's internal structure was primarily a consequence the very small size of the sample used to validate the instrument $(n=47)$. For this reason, Miller, Allen, Casey, and Johnson (2000) conducted a factor analysis of the instrument. Results showed that the OIQ is one-dimensional and that only 12 out of the 25 items make significant contributions to the scale. It was further found that those 12 items measure organizational commitment rather than organizational identification.

The difference between committed employees and employees that identify with the organization is that the first group believes that their place of employment is good and that it best satisfies their needs. They are not 
looking for a new job and express positive feelings towards the organization (Dunham, Grube, \& Castaneda, 1994; Mathieu \& Zajac, 1990). On the other hand, members of the second group have self-images that build on the image of the organization (Cheney, 1982, 1983a, 1983b; Tompkins \& Cheney, 1983, 1985); Furthermore, when employees adopt organizational values and goals, they will engage in decision-making that is consistent with the values and goals of the organization (Barker \& Tompkins, 1994; Tompkins \& Cheney, 1983).

\section{Reference Scales}

The authors took into account the contributions of Van Dick, Wagner, Stellmacher, Christ, and Tissington (2005) in the process of developing SOIS-12. According to such authors, social identity has three components: (1) cognitive, that refers to individuals' knowing that they belong to a particular social group; (2) affective, that refers to the feelings associated to being part of a particular social group; and (3) evaluative, which is related to the positive or negative judgments they make about the group we belong to (collective self-esteem).

\section{Method}

\section{Sample}

Study participants were 224 males $(62.05 \%)$ and 137 females $(37.95 \%)(n=361)$. All of them were employees of 16 fast food restaurants in the City of Monterrey and surrounding metropolitan area. The mean age of the sample is 16.76 years $(S D=4.99)$; the mean length of employment is 10.71 months $(S D=12.99)$ and the mean number of years of education is $9.33(S D=3.31)$.

\section{Instruments}

Researchers developed a scale comprising 30 items (15 positive and 15 negative) which built on the OIQ developed by Mael and Ashforth (1992). Researchers attempted to develop a more valid scale given that the OIQ has been the object of scholarly criticisms.

Examples of selected items are: (1) I adopt attitudes that promote the positive image of our business; (2) The employees of our restaurant represent a united group; (3) I behave as though I'm little help to the positive image of the business; and (4) The employees of our restaurant represent a disunited group. A four-point scale was used to answer the survey items as follows: Positive items are scored: $4=$ "Yes", 3 = "I think so", 2 = "I think don't", 1 = "No". Negative items are scored in reversely.

\section{Procedure}

Members of the research team contacted the director of human resources of a fast food chain in Mexico and obtained authorization to conduct the study. The managers of each of the 16 fast food restaurants were responsible for requesting employee participation in the study, for promising confidentiality to them, for obtaining their verbal consent, for administering the survey forms, and for collecting them. Unidentified survey instruments were completed by participants during work hours in selected conference rooms in their respective places of employment. Completed survey forms were collected by each restaurant manager who forwarded them to the researchers.

Researchers tested the content validity of the survey instrument before using it in this study. The instrument was emailed to seven judges who were asked to evaluate each item and indicate if the item was "necessary and indispensable", "recommended" or "unnecessary". Judges emailed their responses to the researchers after they completed their task. Four of the seven judges selected items 2, 12, 17, 28, 30, 35, 37, 44 
and 66 as necessary and indispensable. After receiving this information, members of the research team proceeded to conduct a confirmatory factor analysis on the nine items selected by the majority of the judges.

\section{Data Analysis}

A measurement model was created with the nine items produced by the instrument's content validity and tested by confirmatory factor analysis. This enabled researchers to validate the construct and establish the goodness of fit of the model splitting the sample subjects by gender. The SPSS (version 18) and AMOS (version 21) software programs were used for data analysis.

\section{Study Design}

The study consisted of a cross-sectional, ex post facto survey.

\section{Findings}

Tables 1 and 2 show the findings of the one-dimensional model measurement of SOIS-12. These were obtained through a confirmatory factor analysis, getting also a good level of internal consistency (Cronbach \& Shavelson, 2004).

Table 1

Means and Standards Deviations of Males and Females by Age, Length of Employment, and Level of Education

\begin{tabular}{lcccc}
\hline & AGE & Months employed & Education & $n$ \\
\hline Males & $M=18.13$ & 10.08 & 10.37 & 224 \\
& $D T=2.11$ & 11.48 & 1.17 & 137 \\
Females & $M=17.86$ & 12.14 & 10.40 & \\
& $D T=1.75$ & 15.17 & 1.18 & \\
\hline
\end{tabular}

Note. $\alpha=0.77$ (male), $\alpha=0.80$ (female).

Table 2

Goodness of Fit of the One-Dimensional Measurement Model of SOIS-12

\begin{tabular}{llllllllll}
\hline & CMIN & $D F$ & $p$ & CMIN/DF & NFI & IFI & TLI & CFI & RMSEA \\
\hline Male & 67.179 & 27 & 0.00 & 2.488 & 0.850 & 0.905 & 0.834 & 0.900 & 0.802 \\
Female & 25.766 & 14 & 0.02 & 1.840 & 0.818 & 0.908 & 0.853 & 0.902 & 0.079 \\
\hline
\end{tabular}

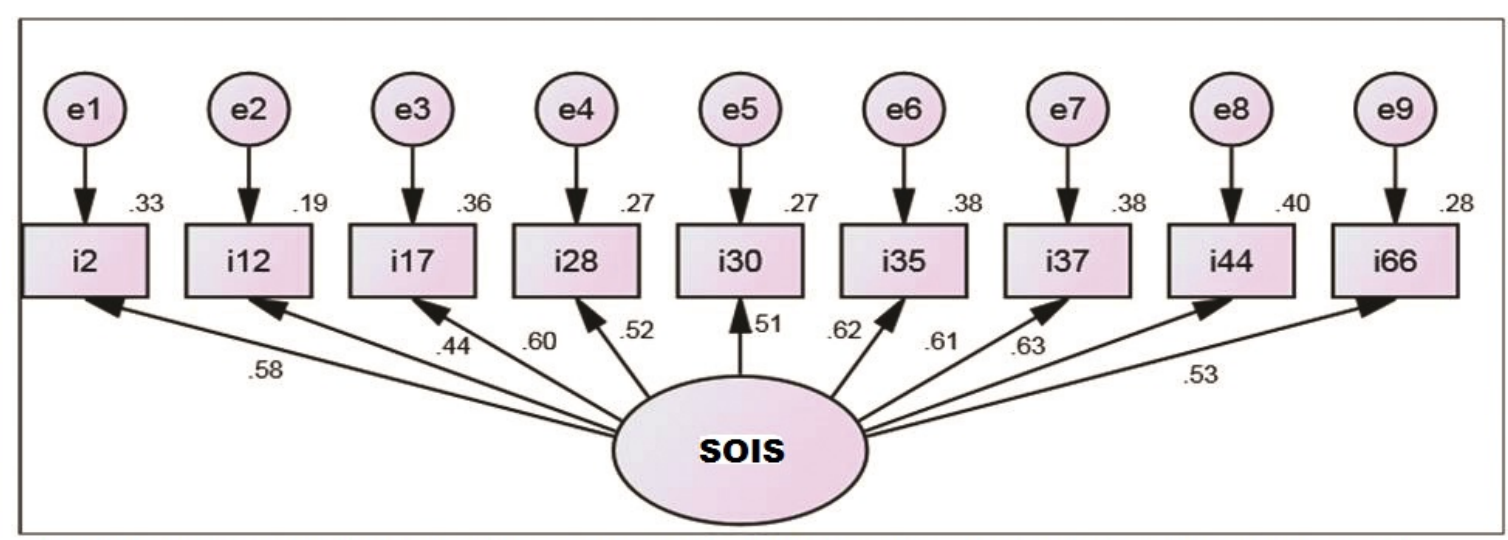

Figure 1. Measurement model using confirmatory factor analysis and linear ordinary squares of SOIS-12 among men. 


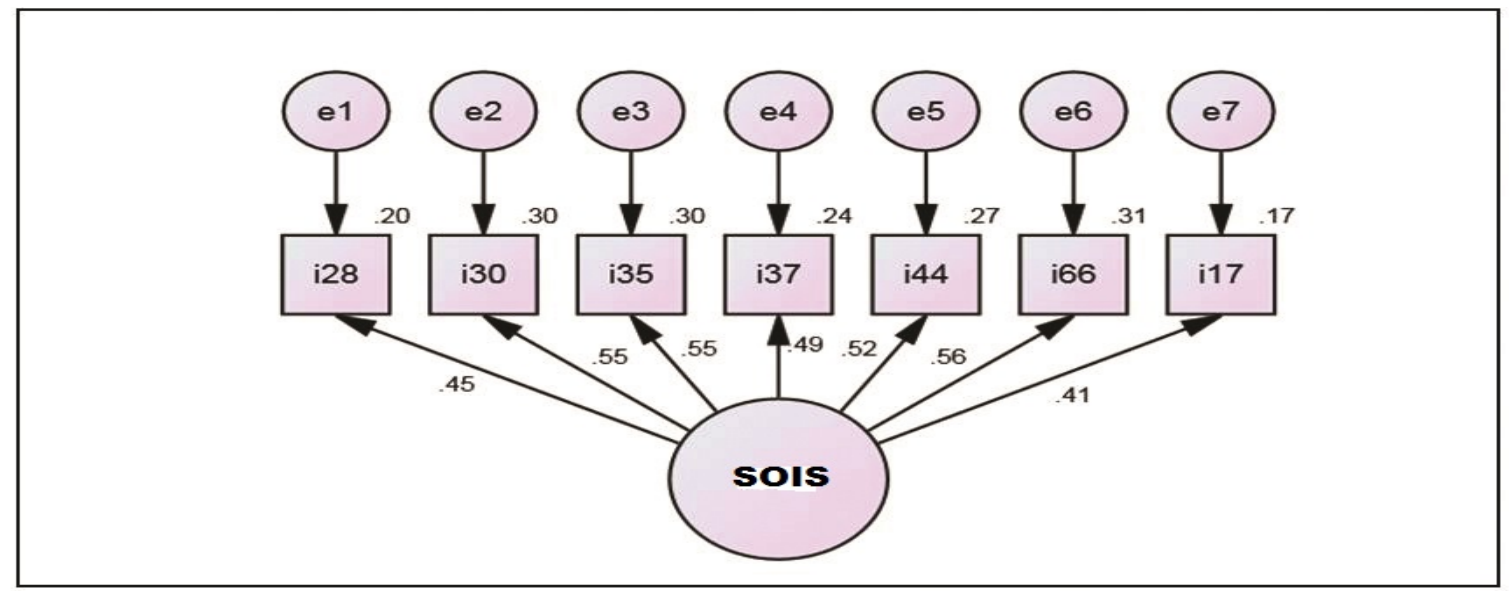

Figure 2. Measurement model for SOIS-12 using confirmatory factor analysis and standardized minimum squares.

The figures graphically illustrate the one-dimensional model of the Social Organizational Identity construct along with the beta values of the responses given to the nine items for males and seven items for females. Figure 1 also shows squared multiple correlations.

As we can see, data reveal an adequate goodness of fit that in turn shows that the nine items make up the social identity organizational construct for males. In contrast, SOIS-12 for females is made up of only seven items. At the same time, the Cronbach alpha values show good internal consistency for both the male sample ( $\alpha$ $=0.77)$ and for the female sample $(\alpha=0.80)$.

\section{Discussion}

As previously indicated, OIQ (Cheney, 1982) has been criticized given that only 12 of the scale's 25 items in the scale significantly contribute to it. Critics have also stated that the scale really measures commitment to the organization and not identification with the organization. Cheney had defined the construct based on Patchen's propositions (Patchen, 1970). According to Patchen, the construct dimensions include: (1) feelings of solidarity or belonging; (2) level of support and loyalty to the organization; and (3) perceived similarity between the values and objectives of the organization and those of the employee.

Other researchers also view the concepts of commitment to the organization and identification with the organization as closely related and even interchangeable concepts. Van Knippenberg and Sleebos (2006), for instance, have attempted to separate or differentiate these two concepts with no success given the broad nature of related studies. According to these authors, identity is a cognitive and perceptual process related to self-reference, self-definition and psychological unity with the organization. Commitment, in turn, reflects an attitude towards the organization and its members, and implies a relationship between the individual and the organization as separate entities.

Rikketa (2005) conducted a meta-analysis of 96 independent samples and found a strong positive correlation between the concepts of organizational commitment and affective social identification with the organization $(r=0.78)$. This finding suggests significant overlap between the two concepts.

Romeo, Berger, Yepes, and Guardia (2011) validated the questionnaire of Quijano et al. (2000) that attempted to measure "Identification with the Organization" and "Commitment to the Organization". The questionnaire was validated for a sample of 625 Spanish subjects and a sample of 520 Portuguese subjects who 
were employees of health service organizations. Their questionnaire contains a total of 20 items related to both constructs. According to Quijano et al. (2000), the theoretical model underlying this instrument to measure organizational commitment is a third level factor that comprises two second level factors. Identification with the organization is conceptualized as having only one dimension. The model used to measure this concept includes a first level factor that in turn is composed of eight observable variables. These include: categorization, pride, cohesion and an item that aims at measuring identification in general. The resulting alpha values included an overall Cronbach alpha of 0.91 , an alpha of 0.87 for the commitment to values subscale, an alpha of 0.88 for the affective commitment subscale, an alpha of 0.89 for the commitment to change subscale, an alpha of 0.91 for the need for commitment subscale, and an alpha of 0.94 for the identification subscale.

The goodness of fit indicators for the Identification-Commitment Inventory is: overall, RMSEA $=0.028$ and CFI $=0.994$, Spanish sample, RMSEA $=0.033$ and CFI $=0.986$ and Portuguese sample, RMSEA $=0.081$ and $\mathrm{CFI}=0.912$.

Prior studies (Romeo, Yepes, Berger, Guardia, \& Castro, 2010) using this instrument have identified overall Cronbach alpha values as high as 0.941. Quijano et al. (2000) in turn have identified the following alpha values: 0.67 for commitment, 0.67 for affective commitment, 0.63 for commitment to change, 0.82 for need for commitment, and 0.93 for identification. Furthermore they found commitment and identification to be significantly correlated $(r=0.50, p<0.05)(r=0.83, p<0.05)$.

SOIS-12 has been developed for a particular organization based on the premise that each organization possesses very unique socio-economic, political and cultural characteristics. This makes this instrument even more valuable. In our opinion, the development of a scale that takes into account the uniqueness of a given organization, significantly contributes to the field of organizational psychology. The scale has specifically focused on the cognitive, affective and evaluative components.

This study sought to develop a SOIS-12 especially designed for a Latin American business enterprise with very unique socio-economic, cultural characteristics in harmony with the authors' conviction that more culturally appropriate scales are needed that take into account the idiosyncrasy of targeted populations (García, Carrascosa, \& Díaz 2013). The authors believe in the value of creating new scales with latent variables already included in other instruments, which satisfy solid psychometric properties of populations with contextual differences such as the Anglo-Saxon and the Latin American.

Research findings show that the internal consistency index for OIQ is 0.90 in samples ranging from 26 to 68 subjects when 12 to 20 items were used. This finding contrasts with that of Cheney (1982) who reported that most of the internal consistency was provided by 11 out of the 25 items. Subsequent studies using at least five items have produced Cronbach aphas above 0.90 while studies using only four items have obtained alphas values going from 0.76 to 0.87 .

Quijano's ICI scale (Quijano et al., 2000) shows an overall alpha value of 0.94 . A factor analysis of his scale however shows the instrument comprises items related to organizational commitment as well as items related to identification with the organization.

The alpha values for SOIS-12 $(n=361)$ are 0.77 for males (nine items) and 0.80 for females (seven items). The confirmatory factor analyses established the one-dimensional nature of the Social Identity organizational construct for both genders. These findings differ from those of Knippenberg and Sleebos (2006), who were reportedly unable to separate or differentiate these two constructs given the broad nature of available studies. 
Findings also differ from those of Romeo et al. (2011) when they validated Quijano et. al.'s scale (2000). Such scale integrated the concepts of organizational identity and organizational commitment.

The findings of this study provide support for the content validity and construct validity of a Latin American instrument to measure social organizational identity. This instrument may enable the executives of this business organization to make informed decisions related to the management of their human resources.

The limitations of this study include that it relied on a sample of convenience composed of employees working for a particular fast food chain in Monterrey, Mexico. This means that the findings of this study cannot be generalized to other organizations, cities or countries. It would have been desirable to include employees from the same organization from other cities in Mexico or employees from other organizations of similar or different types. This would have helped us validate the instrument for other populations.

Finally, we did not simultaneously use the Cheney scale (1982) in this study. This would have enabled us to test the convergent validity of SOIS-12.

\section{References}

Arbuckle, J., \& Wothke, W. (1999). Amos 4.0 user's guide. Chicago: SPSS Inc.

Ashforth, B. E., \& Mael, F. (1989). Social identity theory and the organization. Academy of Managemente Review, 14(1), 20-39.

Ashforth, B., Harrison, S., \& Corley, K. (2008). Identification in organizations: An examination of four fundamental questions. Journal of Management, 34(3), 325-374.

Barker, J. R., \& Tompkins, P. K. (1994). Identification in the self-managing organization: Characteristics of target and tenure. Human Communication Research, 21, 247-264.

Cheney, G., \& Tompkins, P. K. (1987). Coming to terms with organizational identification and commitment. Central States Speech Journal, 38, 1-15.

Cheney, G. (1982). Organizational identification as process and product: A field study (Unpublished master's thesis, Purdue University).

Cheney, G. (1983a). The rhetoric of identification and the study of organizational communication. Quarterly Journal of Speech, 69, 143-158.

Cheney, G. (1983b). On the various and changing meanings of organizational membership: A field study of organizational identification. Communication Monographs, 50, 342-362.

Cronbach, L. J., \& Shavelson, R. J. (2004). My current thoughts on coefficient alpha and successor procedures. Educational and Psychological Measurement, 64(3), 391-418.

Dunham, R. B., Grube, J. A., \& Castaneda, M. B. (1994). Organizational commitment: The utility of an integrative definition. Journal of Applied Psychology, 79, 370-380.

García, C. H., Carrascoza, C. A., \& Díaz, H. L. (2013). Psychological theory and research in Mexico: Critical reflections. International Journal of Psychology Research, 8(2). (in press)

Haslam, S. A., \& Ellemers, N. (2005). Social identity in industrial and organizational psychology: Concepts, controversies and contributions. In G. P. Hodgkinson, \& J. K. Ford (Eds.), International review of industrial and organizational psychology (Vol. 20, pp. 39-118). Chichester: Wiley.

Mael, F., \& Ashforth, B. E. (1992). Alumni and their alma mater: A partial test of the reformulated model of organizational identification. Journal of Organizational Behavior, 13, 103-123

Mathieu, J. E., \& Zajac, D. M. (1990). A review and meta-analysis of the antecedents, correlates, and consequences of organizational commitment. Psychological Bulletin, 108, 171-194.

Miller, V., Allen, M., Casey, M., \& Johnson, R. (2000). Reconsidering the organizational identification questionnaire. Management Communication Quarterly, 13(4), 626-658.

Patchen, M. (1970). Participation, achievement and involvement on the job. New Jersey: Prentice-Hall.

Podsakoff, P. M., Ahearne, M., \& MacKenzie, S. B. (1997). Organizational citizenship behavior and the quantity and quality of work group performance. Journal of Applied Psychology, 82, 262-270.

Postmes, T., \& Jetten, J. (2006). Individuality and the group: Advances in social identity. London: Sage. 
Quijano, S., Navarro, J., \& Cornejo, J. M. (2000). Un modelo integrado de compromiso e identificación con la organización: análisis del cuestionario (An integrated model of commitment and identification with the organization: An analysis of the questionnaire). ASH-ICI. Revista de Psicología Social Aplicada, 10, 27-61.

Real Academia de la Lengua (2001, 22ava. Ed.). Diccionario de la Real Academia de la Lengua Española (Dictionary of the Royal Academy of the Spanish Language). Barcelona: Océano.

Riketta, M. (2005). Organizational identification: A meta-analysis. Journal of Vocational Behavior, 66, 358-384.

Romeo, M., Yepes, M., Berger, R., Guárdia, J., \& Castro, C. (2010). Identification-commitment inventory (ICI Model): Confirmatory factor analysis and construct validity. Quality and Quantity. doi: 10.1007/s11135-010-9402-0.

Romeo, M., Berger, R., Yepes, M., \& Guárdia, J. (2011). Equivalent validity of identification-commitment-inventory (HSA-ICI). Escritos de Psicología, 4(1), 1-8.

Tajfel, H. (1974). Social identity and intergroup behaviour. Social Science Information, 13, 65-93.

Tajfel, H. (Ed.). (1978). Diferenciación entre grupos sociales: Estudios en la psicología social de las relaciones intergrupales (Differentiation of social groups: Social psychology studies about intergroup relations). London: Academic Press.

Tajfel, H., \& Turner, J. (1981). Human groups and social categories. In T. Henri (Ed.), Interative theory of intergroups conflict (pp. 33-47). Cambridge: Cambrige University Press.

Tajfel, H., \& Turner, J. (1986). The social identity theory of inter-group behavior. In S. Worchel, \& L. W. Austin (Eds.), Psychology of intergroup relations. Chigago: Nelson-Hall.

Tompkins, P. K., \& Cheney, G. (1983). Account analysis of organizations: Decision-making and identification. In L. Putnam, \& M. Pacanowsky (Eds.), Communication and organizations: An interpretive approach (pp. 123-146). Beverly Hills, C.A.: Sage.

Tompkins, P. K., \& Cheney, G. (1985). Communication and unobtrusive control in contemporary organizations. In R. D. McPhee, \& P. K. Tompkins (Eds.), Organizational communication: Traditional themes and new directions (pp. 179-210). Beverly Hills, C.A.: Sage.

Tompkins, J. R. (2005). Organization theory and public management. Thomson Wadsworth, Belmont, C.A.

Topa, G., \& Morales, J. F. (2006). Identificación organizacional y proactividad personal en grupos de trabajo: Un modelo de ecuaciones estructurales (Organizational identification and personal proactivity in work groups: A structural equations model). Anales de Psicología, 22(2), 234-242.

Van Knippenberg, D., \& Ellemers, N. (2003). La identidad social y el desempeño del grupo: Identificación como la clave para los esfuerzos orientados al grupo (Social identity and group performance: Identification as the key for collective efforts). In S. A. Haslam, D. van Knippenberg, M. J. Platow, \& N. Ellemers (Eds.), La identidad social en el trabajo: El desarrollo de la teoria de la práctica organizacional (Social identity in the workplace: The development of the organizational practice theory) (pp. 29-42). Nueva York and Hove, United Kingdom: Psychology Press.

Van Knippenberg, D., \& Van Schie, E. (2000). Foci and correlates of organizational identification. Journal of Occupational and Organizational Psychology, 73(2), 137-147.

Van Knippenberg, D., \& Sleebos, E. (2006). Organizational identification versus organizational commitment: Self-definitions, social exchange, and job attitudes. Journal of Organizational Behavior, 27, 585-605.

Van Dick, R., Wagner, U., Stellmacher, J., Christ, O., \& Tissington, P. (2005). To be (long) or not to be (long): Social identification in organizational context. Genetic, Social and General Psychology Monographs, 131(3), 189-218.

Yubero, S., \& Morales, J. F. (2006). La identificación en las organizaciones y su relación con la prototipicidad y el conflicto entre grupos profesionales (Identification in organizations and its relation to prototypicality and conflict among professional groups). Psicothema, 18(3), 400- 406. 